\title{
Architecture and Mental Disorders: A Systematic Study of Peer-Reviewed Literature
}

(C) The Author(s) 2020

Article reuse guidelines: sagepub.com/journals-permissions DOI: 10.1 I 77/1937586720973767 journals.sagepub.com/home/her

(SAGE

\author{
Mais M. Aljunaidy, MD, MRes, PhD' ${ }^{\oplus}$, \\ and Mohamad Nadim Adi, BARCH, MA, PhD ${ }^{2}$
}

\begin{abstract}
Objectives: To perform a systematic study about the contribution of architecture and interior design researchers in studying the effect of physical environment on mental disorders. Background: Mental disorders are a major health problem worldwide and related to severe distress, functional disabilities, and heavy economical burdens. Studies propose that physical environment design can trigger or reduce mental disorder symptoms. However, there is a lack of knowledge about the extent of architectural design research contribution to all types of mental disorder prevention or intervention. Methods: A team of cross-disciplinary researchers gathered information from peer-reviewed manuscripts about the effect of architectural design on enhancing or reducing mental disorder symptoms. Data were collected from manuscripts published between 2008 and 2020 (research related to the topic became clearer in quality and quantity then). Keywords including architecture, interior design, physical environment, and mental disorders were used in the systematic search. Databases were collected using online resources. Numerical data collected from quantitative studies were organized in tables. Results: Our data showed that there were a lot of studies about dementia and autism; few studies about schizophrenia, anxiety, stress-related disorders, and depressive disorders; and no studies about the rest of the mental disorders. General environment followed by housing facility design were the most assessed physical environments for mental disorders. Conclusions: As all mental disorders can have a significant impact on the society, we conclude that architectural studies should focus more on improving or preventing the symptoms of all types of mental disorders through the design of physical environments.
\end{abstract}

\footnotetext{
'Psychology Department, Interdisciplinary Program in Neuroscience, Faculty of Economics, Administrative, and Social Sciences, Bilkent University, Ankara, Turkey

${ }^{2}$ Department of Interior Architecture and Environmental Design, Faculty of Art, Design and Architecture, Bilkent University, Ankara, Turkey

Corresponding Author:

Mohamad Nadim Adi, BARCH, MA, PhD, Department of Interior Architecture and Environmental Design, Faculty of Art, Design and Architecture, Bilkent University, TR-06800 Bilkent, Ankara, Turkey.

Email: nadim.adi@bilkent.edu.tr
} 


\section{Keywords}

architecture, mental disorders, interior design, physical environments, systematic study

Mental disorders are a major health problem worldwide, affecting over 165 million people each year (Kessler et al., 2012; Wittchen et al., 2011). More than half of the general population in middle- and high-income countries will be diagnosed with at least one mental disorder at some point in their lives (Trautmann et al., 2016). Moreover, mental disorders are related to severe distress, functional disabilities, and heavy economical burdens that account for more than chronic somatic diseases such as cancer or diabetes (Jamison et al., 2016; Trautmann et al., 2016). Furthermore, with the growing human population, the long-term burden of mental disorders is expected to increase (Jamison et al., 2016). Consequently, and considering the serious impact of mental disorders on individuals and societies alike, there was a need for a greater support of people with mental disorders. Over the years, architects focused on creating designs that are related to normal human psychology and behavior, such as socializing, and industry-related performance, such as the improvement of visitors' experiences in hotels or museums, and increasing the possibility of buying a product such as in supermarkets and malls (El-Zeiny, 2012; Shojazadeh et al., 2014; Yalçin, 2015). However, physical environment can also trigger or mitigate mental disorder symptoms (Benedetti et al., 2001; Karami, 2016; Khanade et al., 2018; Kinnaer et al., 2016; McAllister \& Maguire, 2012; Parke \& Friesen, 2007; Parke et al., 2017). Therefore, and giving the importance of physical environment design in the well-being of people suffering from mental disorders, architects need to develop clear design recommendations that are safe for people with mental disorders (Connellan et al., 2013). Thus, an up-to-date systematic study is required to highlight what has been done so far regarding the contribution of architectural design research to mental disorder prevention or intervention. What we meant about architectural design is everything that architects and interior designers can contribute to its designing and implementing in physical environments which can range from space to calling buttons.

\section{...physical environment can also trigger or mitigate mental disorder symptoms.}

\section{Therefore, and giving the importance of} physical environment design in the well-being of people suffering from mental disorders, architects need to develop clear design recommendations that are safe for people with mental disorders

Studies showed that physical environment design can trigger mental disorder symptoms. For example, dementia patients see shadows as holes. Therefore, the placement of lights in a way that forms shadows can cause trouble to people with dementia and makes them walk in a strange and sometimes unsafe way (Parke et al., 2017). Furthermore, for dementia patients, some exits should be hidden with plants or camouflaged by the same color of the wall. Otherwise, dementia patients can get agitated if they cannot open those doors (Parke et al., 2017). Further, design features such as sharp corners, blind spots, and narrow pathways can increase anxiety and can trigger post-traumatic stress disorder in veterans (Khanade et al., 2018). Another example is pupils with autism who might show unstable emotions such as screaming if they are transferred into a classroom that is not similar to other mainstream classroom environments they used to go to (McAllister \& Maguire, 2012).

Physical environments do not only trigger mental disorder symptoms but can reduce mental disorder symptoms too. For example, architectural design can improve dementia patient's vision and recognition by providing direct cues toward environmental surroundings, removing attention distracting objects, and highlighting or camouflaging key features in the living 
environments (Parke \& Friesen, 2007). Furthermore, an interior design study found that exposure to morning sunlight can reduce the length of hospitalization in bipolar depressed patients (Benedetti et al., 2001). Other studies also showed that designing space dedicated to yoga in hospitals can improve the precision, focus, and thinking of schizophrenia patients (Karami, 2016). Designing roof as a space to watch the urban landscape as well can reduce the feeling of withdrawal from society in schizophrenia patients (Karami, 2016). Furthermore, open spaces, situational awareness providing elements in the surrounding environment such as open floor plans, or the lack of clutter can relax veterans who are suffering from post-traumatic stress disorder (Khanade et al., 2018). In autistic patients, a space that is subdivided into several separate spaces helped in creating a sense of structure and reduced sensory inputs present in one room (Kinnaer et al., 2016).

As it is already established that physical environment designs can trigger or prevent mental disorder symptoms, there is a need to know to what extent researchers are linking environmental design studies with mental disorders, and what mental disorders they are focusing on the most. This review article will provide an overview about the number of peer-reviewed manuscripts that assessed the effect of architectural design on each type of mental disorders. The current review will also highlight the design features that were used by architects to study mental disorders in physical environments. As mental disorders in general have a significant social and emotional impact on individuals and societies (Angermeyer et al., 2010; Doran \& Kinchin, 2019), this article will give a general idea of what mental disorders architects are focusing on the most in their studies and what mental disorders should get more attention in future architectural design research. The purpose is to encourage more architectural studies to be done about how physical environment can impact the symptoms of all types of mental disorders and to encourage further collaborations between architects and psychologists to provide a better understanding of building designs that support mental stability and well-being of people suffering from mental disorders.

\section{... what mental disorders should get more attention in future architectural design research.}

\section{Method}

\section{Data Collection}

In order to assess to what extent researchers are linking environmental design with mental disorders, and what mental disorders they are focusing on the most, a team of two cross-disciplinary researchers gathered information from peer-reviewed manuscripts that assessed the effect of architectural design on enhancing or reducing mental disorder symptoms. Data were collected from manuscripts published between 2008 and 2020 inclusive (interest in mental disorders and physical environment became clearer in quality and quantity in 2008, thus manuscripts before 2008 were excluded). Databases were collected using the internet through the following websites: Google, Google Scholar, PubMed, and Web of Science. The mentioned websites provided sufficient material to form a good understanding of the current state of physical environment design research and mental disorders. Key words that were sufficient to this paper's aim were used for the systematic search. These key words were architecture, internal design, physical environment, and mental disorders (the type of each mental disorder was specified). The aim of this article was to highlight the imbalance within architectural design studies that focus on all types of mental disorders. Looking specifically into all the possible ranges of vocabulary related to design and mental disorders would overwhelm us with the amount of data. Numerical data collected from quantitative studies were organized in tables. Mental disorders which were covered in this study were neurodevelopmental disorders, bipolar and related disorders, anxiety disorders, 
stressor-related disorders, dissociative disorders, somatic symptom and related disorders, feeding and eating disorders, sleep-wake disorders disruptive, impulse-control and conduct disorders, depressive disorders, substance-related and addictive disorders, neurocognitive disorders (e.g., dementia), schizophrenia obsessive-compulsive and related disorders, and personality disorders. The architectural aspects that were assessed regarding physical environments and their effects on mental disorders studies were space, visual support, auditory support, and environmental elements such as number of windows and doors, hallways, room layout, blind spots, handrails, call buttons, seats, decorations, and direct sightlines. The physical environments in our study were divided into teaching facilities, healthcare facilities, housing (living) facilities, and general environments (when the study did not specify the physical environment and talked about it in general). Aged-care environment papers are outside the scope of our article's topic and thus were not included in our review. Papers that discuss the design and mental disorder in general without specification of what is the mental disorder they are talking about do not serve the purpose of our article, and therefore, they were excluded.

\section{Results}

\section{Architectural Studies Focused the Most on Few Mental Disorders}

Our data showed that architectural studies focused more on some mental disorders compared to other mental disorders (Table 1). There were a lot of studies about dementia and autism; few studies about schizophrenia, anxiety disorders, stress-related disorders, and depressive disorders; and no studies about the rest of mental disorders. Overall, light was the most studied design element in all mental disorders combined. Light was assessed in all the listed studies in Table 1 except in anxiety disorder studies. The importance of light could be due to the role of the light/dark cycle in the nervous system well-being (Blume et al., 2019).

\section{Dementia and Autism Were the Most Covered Mental Disorder Topics in Architecture and Design Research Papers}

Dementia and autism were the most assessed mental disorders in architectural studies (Table 2). In dementia, the focus was mainly on housing facilities, while in autism, the focus was mainly on teaching facilities.

Most architectural studies related to mental disorders were assessing physical environments in general. However, the impact of housing facility design on mental disorders was the most common specific environment covered by architectural studies regarding mental disorders (Table 2).

\section{Discussion}

Our data showed for the first time the great focus of architectural studies on some mental disorders at the expense of other mental disorders. For instance, there were many architectural study publications about the effect of physical environment design on two mental disorders which were dementia and autism. However, there were no architectural peer-reviewed manuscripts about the effect of built environment design on other mental disorders which were neurodevelopmental disorders, dissociative disorders, somatic symptom and related disorders, eating disorders, sleep-wake disorders, disruptive, impulse-control, and conduct disorders, obsessive-compulsive and related disorders, and personality disorders. Furthermore, anxiety, mood, and substance use disorders are the most common mental disorders worldwide (Kessler et al., 2012; Wittchen et al., 2011), yet there were not as much physical environment design studies about them as dementia and autism. The bigger research interest in the effect of physical environment design on dementia and autism compared to the rest of mental disorders is yet to be understood. However, we speculate that demand could be one of the factors. For example, in autism, there is an urge for teaching facilities at a certain age of the child's life (Gerhardt \& Lainer, 2011). Autism affects children at early stages of life, and its symptoms become clear as early as the third year of age. This means that soon after, children with autism will need specialized day cares and teaching facilities. 


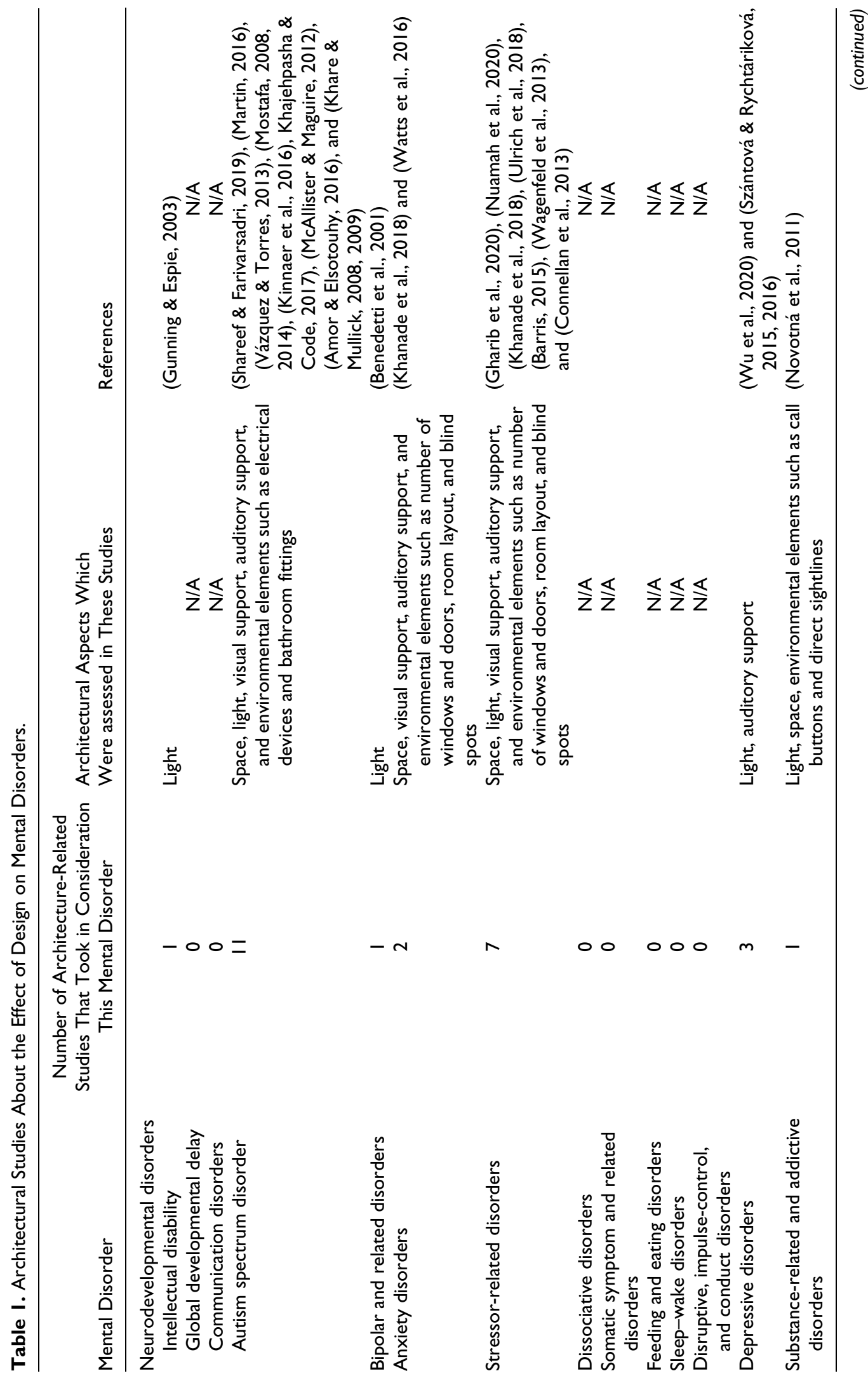




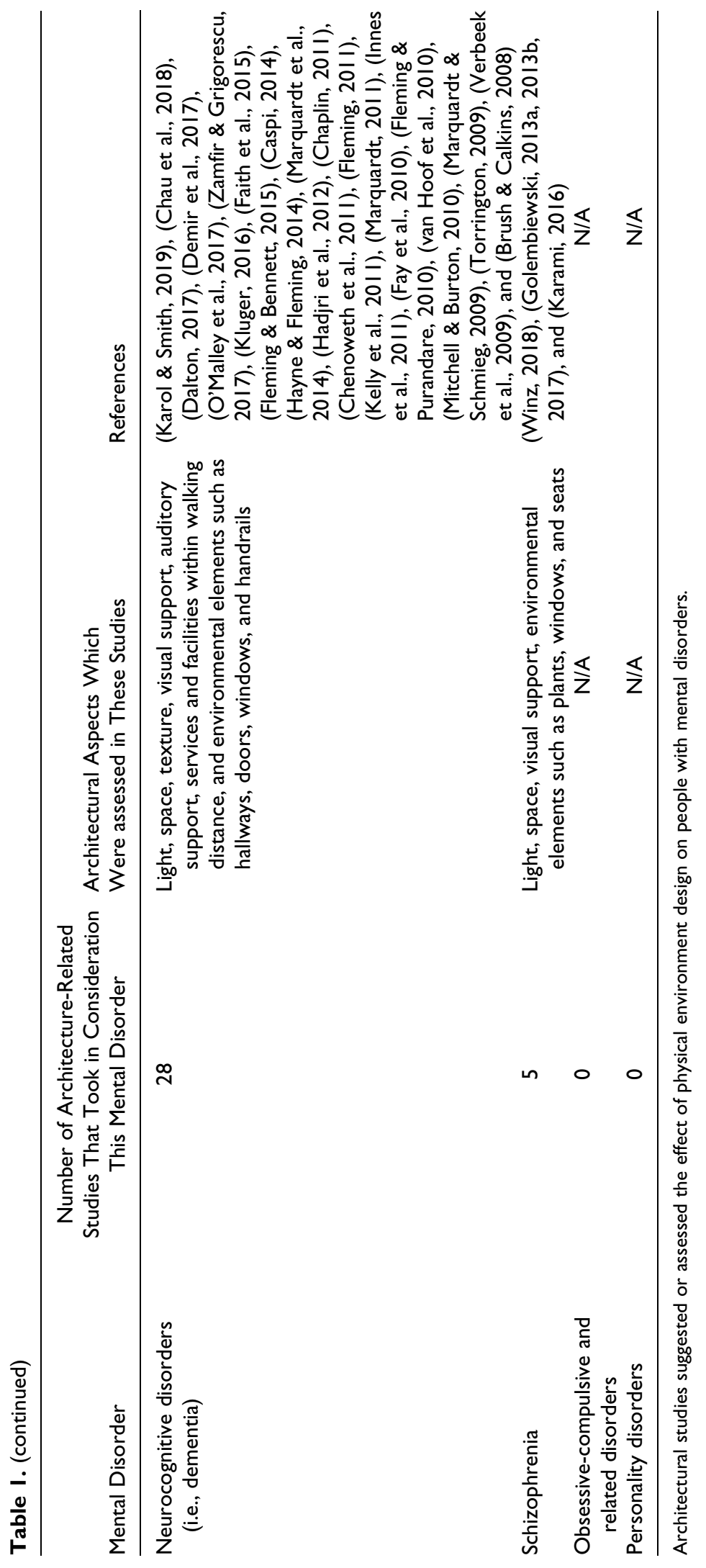


Table 2. Distribution of Architectural Studies Depending on the Type of the Facility and the Type of Mental Illness.

\begin{tabular}{|c|c|c|c|}
\hline $\begin{array}{l}\text { Physical } \\
\text { Environment }\end{array}$ & $\begin{array}{l}\text { Number of Architectural } \\
\text { and Interior Design } \\
\text { Studies Related to } \\
\text { Mental Disorders }\end{array}$ & $\begin{array}{l}\text { Percentage of Architectural } \\
\text { Studies Related to Mental } \\
\text { Disorders to the Total } \\
\text { Number of the Performed } \\
\text { Studies (\%) }\end{array}$ & $\begin{array}{l}\text { Distribution of Mental } \\
\text { Disorders That Were } \\
\text { Assessed in Each Physical } \\
\text { Environment }\end{array}$ \\
\hline Teaching facilities & 6 & 10 & $100 \%$ autism \\
\hline Healthcare facilities & 7 & 12 & $\begin{array}{l}71 \% \text { dementia, } 14.5 \% \\
\text { schizophrenia, } 14.5 \% \\
\text { addiction }\end{array}$ \\
\hline Housing facilities & 19 & 33 & $\begin{array}{l}68 \% \text { dementia, } 21 \% \text { stress, } \\
11 \% \text { schizophrenia }\end{array}$ \\
\hline General environments & 27 & 45 & $\begin{array}{l}41 \% \text { dementia, } 30 \% \text { autism, } \\
4 \% \text { intellectual disability, } \\
12 \% \text { stress, } 11 \% \\
\text { depression, } 7 \% \text { anxiety, } \\
\text { and } 7 \% \text { schizophrenia }\end{array}$ \\
\hline
\end{tabular}

Giving the special needs for those children, clear standards of day care and classroom designs are needed. In dementia, however, the illness usually develops at an advanced age and the patients start to have gradual deterioration in their cognition and memory. With these mental restrictions in dementia, families start to look for safe housing facilities and environments that can protect their beloved ones from the disorientation symptoms and self-injuries (Hadjri et al., 2015).

On the other hand, in mental disorders that happen in early adulthood, such as eating disorders, schizophrenia, and depression, one of the possible reasons of gaining less interest by physical environment design researchers is that patients and their families do not seem to seek much help regarding specifications of special built environments. However, future studies are needed to confirm and clarify this matter. Another possible factor of the imbalanced research design studies regarding mental disorders might be due to the shortage in understanding what might relief part of a person mental disorder symptoms such as extreme situations of schizophrenia when the patient cannot express feelings about the ideal physical environment.

All mental disorders can have a significant impact on the quality of life of individuals suffering from mental disorders and their families and can cause a strain on the health system and societies in general (Patel et al., 2007; Pitkänen et al., 2009; Swanson et al., 1997). Our article agrees with a previous study by Connellan et al. (2013) about the importance of architectural design studies on providing a safe environment and support for people with mental disorders. However, in Connellan et al.'s study, the focus was on design features and how they might be shaped or modified to serve people with mental disorders. Herein, we wanted to know what mental disorders are gaining the most interest in architectural and interior design research and what mental disorders are getting the least focus regarding their link to physical environments. We aimed in this review to encourage architecture researchers to start considering the study of built environment effect on all mental disorders without an exception, especially those mental disorders that have not been taken in consideration previously in architectural studies.

Further studies as well are important to assess to what extent people understand the importance of physical environments on triggering or preventing mental disorder symptoms. We think that architects need to have a stronger and clearer database in terms of design for all mental disorder facilities including housing, learning, and healthcare environments. More studies are needed as 
well to understand architecture researchers' viewpoints regarding creating design standers to support all mental illnesses.

We conclude that there is a shortage in the optimal physical environment design recommendations to improve or avoid the triggers of symptoms of most mental disorders. Architects should focus more on improving or preventing the symptoms of all types of mental disorders through their design tools of physical environments and through collaboration and consultation with mental disorder experts such as psychologists and psychiatrists.

\section{Implications for Practice}

- Architects should focus more on improving or preventing the symptoms of all types of mental disorders through their design tools of physical environments.

- Architects should consult and collaborate with human mental illnesses experts such as psychologists and psychiatrists to create a stronger and clearer database in terms of design for all mental disorder facilities including housing, learning, and healthcare environments.

- More studies are needed also to understand architectural researchers' viewpoints regarding creating design standers to support all mental illnesses.

\section{Declaration of Conflicting Interests}

The authors declared no potential conflicts of interest with respect to the research, authorship, and/or publication of this article.

\section{Funding}

The authors received no financial support for the research, authorship, and/or publication of this article.

\section{ORCID iD}

Mais M. Aljunaidy, MD, MRes, PhD (D) https:// orcid.org/0000-0003-4738-0365

\section{References}

Amor, M. C., \& Elsotouhy, A. (2016). Neuroscience and interior architecture: Impact on autism [Paper presentation]. Qatar Foundation Annual Research Conference Proceedings. http://dx.doi.org/10.533 9/qfarc.2016.SSHAPP1744.

Angermeyer, M. C., Holzinger, A., \& Matschinger, H. (2010). Emotional reactions to people with mental illness. Epidemiologia e Psichiatria Sociale, 19(1), 26-32. https://doi.org/10.1017/s1121189x000 01573

Barris, K. (2015). Designing healing environments in veteran housing for those coping with posttraumatic stress disorder. California State University.

Benedetti, F., Colombo, C., Barbini, B., Campori, E., \& Smeraldi, E. (2001). Morning sunlight reduces length of hospitalization in bipolar depression. Journal of Affective Disorders, 62(3), 221-223.

Blume, C., Garbazza, C., \& Spitschan, M. (2019). Effects of light on human circadian rhythms, sleep and mood. Somnologie, 23(3), 147-156.

Brush, J. A., \& Calkins, M. P. (2008). Environmental interventions and dementia: Enhancing mealtimes in group dining rooms. The ASHA Leader, 13(8), 24-25.

Caspi, E. (2014). Wayfinding difficulties among elders with dementia in an assisted living residence. Dementia, 13(4), 429-450.

Chaplin, A. (2011). Holistic care and environmental design: The future for dementia care. Housing, Care and Support, 14(3), 91-97.

Chau, H.-W., Newton, C., Woo, C., Ma, N., Wang, J., \& Aye, L. (2018). Design lessons from three Australian dementia support facilities. Buildings, 8(5), 67.

Chenoweth, L., King, M., Luscombe, G., Forbes, I., Jeon, Y. H., Parbury, J. S., Brodaty, H., Fleming, R., \& Haas, M. (2011). Study protocol of a randomised controlled group trial of client and care outcomes in the residential dementia care setting. Worldviews on Evidence-Based Nursing, 8(3), 153-165.

Connellan, K., Gaardboe, M., Riggs, D., Due, C., Reinschmidt, A., \& Mustillo, L. (2013). Stressed spaces: Mental health and architecture. HERD: Health Environments Research \& Design Journal, 6(4), 127-168. 
Dalton, C. (2017). Including smart architecture in environments for people with dementia. In $\mathrm{G}$. Demiris, E. J. M. Wouters, \& J. van Hoof (Eds.), Handbook of smart homes, health care and wellbeing (pp. 335-347). Springer.

Demir, E., Köseoğlu, E., Sokullu, R., \& Şeker, B. (2017). Smart home assistant for ambient assisted living of elderly people with dementia. Procedia Computer Science, 113, 609-614.

Doran, C. M., \& Kinchin, I. (2019). A review of the economic impact of mental illness. Australian Health Review, 43(1), 43-48.

El-Zeiny, R. M. A. (2012). The interior design of workplace and its impact on employees' performance: A case study of the private sector corporations in Egypt. Procedia-Social and Behavioral Sciences, 35, 746-756.

Faith, V., Hadjri, K., Rooney, C., Craig, C., \& McAllister, K. (2015). Finding a way: Long-term care homes to support dementia. Proceedings of the Institution of Civil Engineers-Urban Design and Planning, 168(4), 204-217.

Fay, R., Fleming, R., \& Robinson, A. (2010). Design for dementia: Sustainability and human wellbeing [Paper presentation]. On the Edge, Proceedings of the 44th Annual Conference of the Australian and New Zealand Architectural Science Association, Auckland, New Zealand.

Fleming, R. (2011). An environmental audit tool suitable for use in homelike facilities for people with dementia. Australasian Journal on Ageing, 30(3), $108-112$.

Fleming, R., \& Bennett, K. (2015). Assessing the quality of environmental design of nursing homes for people with dementia: Development of a new tool. Australasian Journal on Ageing, 34(3), 191-194.

Fleming, R., \& Purandare, N. (2010). Long-term care for people with dementia: Environmental design guidelines. International Psychogeriatrics, 22(7), 1084-1096.

Gerhardt, P. F., \& Lainer, I. (2011). Addressing the needs of adolescents and adults with autism: A crisis on the horizon. Journal of Contemporary Psychotherapy, 41(1), 37-45.

Gharib, M. A., Golembiewski, J. A., \& Moustafa, A. A. (2020). Mental health and urban design-zoning in on PTSD. Current Psychology, 39(1), 167-173.

Golembiewski, J. (2013a). Are diverse factors proxies for architectural influences? A case for architecture in the aetiology of schizophrenia. Cureus, 5(3), Article e106.

Golembiewski, J. (2013b). Lost in space: The place of the architectural milieu in the aetiology and treatment of schizophrenia. Facilities, 31(9/10), 427-448.

Golembiewski, J. (2017). Architecture, the urban environment and severe psychosis: Aetiology. Journal of Urban Design and Mental Health, 2(1).

Gunning, M., \& Espie, C. (2003). Psychological treatment of reported sleep disorder in adults with intellectual disability using a multiple baseline design. Journal of Intellectual Disability Research, 47(3), 191-202.

Hadjri, K., Faith, V., \& McManus, M. (2012). Designing dementia nursing and residential care homes. Journal of Integrated Care, 20(5), 322-340.

Hadjri, K., Rooney, C., \& Faith, V. (2015). Housing choices and care home design for people with dementia. HERD: Health Environments Research \& Design Journal, 8(3), 80-95.

Hayne, M. J., \& Fleming, R. (2014). Acoustic design guidelines for dementia care facilities. https://ro. uow.edu.au/smhpapers/2640/.

Innes, A., Kelly, F., \& Dincarslan, O. (2011). Care home design for people with dementia: What do people with dementia and their family carers value? Aging \& Mental Health, 15(5), 548-556.

Jamison, D. T., Nugent, R., Gelband, H., Horton, S. E., Jha, P. K., Laxminarayan, R., \& Mock, C. N. (2016). Mental, neurological, and substance use disorders. The World Bank.

Karami, E. (2016). Architecture for specific disease case study in schizophrenic patients. International Journal of Biomedical and Advance Research, 7, 001-004.

Karol, E., \& Smith, D. (2019). Impact of design on emotional, psychological, or social well-being for people with cognitive impairment. HERD: Health Environments Research \& Design Journal, 12(3), 220-232.

Kelly, F., Innes, A., \& Dincarslan, O. (2011). Improving care home design for people with dementia. Journal of Care Services Management, 5(3), 147-155.

Kessler, R. C., Petukhova, M., Sampson, N. A., Zaslavsky, A. M., \& Wittchen, H. U. (2012). Twelve-month and lifetime prevalence and lifetime morbid risk of anxiety and mood disorders in the 
United States. International Journal of Methods in Psychiatric Research, 21(3), 169-184.

Khajehpasha, S. S., \& Code, Q. (2017). School architecture for autism children. International Journal of Biomedical and Advance Research, 8, 72-75.

Khanade, K., Rodriguez-Paras, C., Sasangohar, F., \& Lawley, S. (2018). Investigating architectural and space design considerations for post-traumatic stress disorder (PTSD) patients [Paper presentation]. Proceedings of the Human Factors and Ergonomics Society Annual Meeting. https://ro.uow. edu.au/smhpapers/2640/.

Khare, R., \& Mullick, A. (2008). Educational spaces for children with autism: Design development process. Environments, 15, 16.

Khare, R., \& Mullick, A. (2009). Incorporating the behavioral dimension in designing inclusive learning environment for autism. Archnet-ijar, 3(3), 45-64.

Kinnaer, M., Baumers, S., \& Heylighen, A. (2016). Autism-friendly architecture from the outside in and the inside out: An explorative study based on autobiographies of autistic people. Journal of Housing and the Built Environment, 31(2), 179-195.

Kluger, S. (2016). Guiding light: The architecture of sleep for dementia.

Marquardt, G. (2011). Wayfinding for people with dementia: A review of the role of architectural design. HERD: Health Environments Research \& Design Journal, 4(2), 75-90.

Marquardt, G., Bueter, K., \& Motzek, T. (2014). Impact of the design of the built environment on people with dementia: An evidence-based review. HERD: Health Environments Research \& Design Journal, 8(1), 127-157.

Marquardt, G., \& Schmieg, P. (2009). Dementiafriendly architecture: Environments that facilitate wayfinding in nursing homes. American Journal of Alzheimer's Disease \& Other Dementias ${ }^{\circledR}$, 24(4), 333-340.

Martin, C. S. (2016). Exploring the impact of the design of the physical classroom environment on young children with autism spectrum disorder (ASD). Journal of Research in Special Educational Needs, 16(4), 280-298.

McAllister, K., \& Maguire, B. (2012). Design considerations for the autism spectrum disorder-friendly Key Stage 1 classroom. Support for Learning, 27(3), 103-112.
Mitchell, L., \& Burton, E. (2010). Designing dementiafriendly neighbourhoods: Helping people with dementia to get out and about. Journal of Integrated Care, 18(6), 11-18.

Mostafa, M. (2008). An architecture for autism: Concepts of design intervention for the autistic user. International Journal of Architectural Research: ArchNet-IJAR, 2(1), 189-211.

Mostafa, M. (2014). Architecture for Autism: Autism ASPECTSS ${ }^{\mathrm{TM}}$ in School Design. International Journal of Architectural Research: ArchNet-IJAR, 8(1), 143-158.

Novotná, G., Urbanoski, K. A., \& Rush, B. R. (2011). Client-centered design of residential addiction and mental health care facilities: Staff perceptions of their work environment. Qualitative Health Research, 21(11), 1527-1538.

Nuamah, J., Rodriguez-Paras, C., \& Sasangohar, F. (2020). Veteran-centered investigation of architectural and space design considerations for posttraumatic stress disorder (PTSD). HERD: Health Environments Research \& Design Journal. https:// doi.org/10.1177/1937586720925554

O’Malley, M., Innes, A., \& Wiener, J. M. (2017). Decreasing spatial disorientation in care-home settings: How psychology can guide the development of dementia friendly design guidelines. Dementia, 16(3), 315-328.

Parke, B., Boltz, M., Hunter, K. F., Chambers, T., Wolf-Ostermann, K., Adi, M. N., Feldman, F., \& Gutman, G. (2017). A scoping literature review of dementia-friendly hospital design. The Gerontologist, 57(4), e62-e74.

Parke, B., \& Friesen, K. (2007). Code plus: Physical design components for an elder friendly hospital. Fraser Health Authority.

Patel, V., Flisher, A. J., Hetrick, S., \& McGorry, P. (2007). Mental health of young people: A global public-health challenge. The Lancet, 369(9569), 1302-1313.

Pitkänen, A., Hätönen, H., Kuosmanen, L., \& Välimäki, M. (2009). Individual quality of life of people with severe mental disorders. Journal of Psychiatric and Mental Health Nursing, 16(1), 3-9.

Shareef, S. S., \& Farivarsadri, G. (2019). The impact of colour and light on children with autism in interior spaces from an architectural point of view. International Journal of Arts and Technology, 11(2), 153-164. 
Shojazadeh, H. R., Kazemi, M., \& Shafizadeh, A. A. (2014). Environmental psychology in architecture and urban design. Research Journal of Recent Sciences, ISSN, 2277, 2502.

Swanson, J., Estroff, S., Swartz, M., Borum, R., Lachicotte, W., Zimmer, C., \& Wagner, R. (1997). Violence and severe mental disorder in clinical and community populations: The effects of psychotic symptoms, comorbidity, and lack of treatment. Psychiatry, 60(1), 1-22.

Szántová, G., \& Rychtáriková, M. (2015). The importance of audio-visual aspects in the architectural design of psychiatric clinics. Energy Procedia, 78, 1251-1256.

Szántová, G., \& Rychtáriková, M. (2016). Architecture indoor environment as a healing factor of depression and seasonal affective disorder [Paper presentation]. Applied Mechanics and Materials. https:// www.scientific.net/AMM.824.210.

Torrington, J. (2009). The design of technology and environments to support enjoyable activity for people with dementia. Alter, 3(2), 123-137.

Trautmann, S., Rehm, J., \& Wittchen, H. U. (2016). The economic costs of mental disorders: Do our societies react appropriately to the burden of mental disorders? EMBO Reports, 17(9), 1245-1249.

Ulrich, R. S., Bogren, L., Gardiner, S. K., \& Lundin, S. (2018). Psychiatric ward design can reduce aggressive behavior. Journal of Environmental Psychology, 57, 53-66.

van Hoof, J., Kort, H. S., Van Waarde, H., \& Blom, M. (2010). Environmental interventions and the design of homes for older adults with dementia: An overview. American Journal of Alzheimer's Disease \& Other Dementias ${ }^{\circledR}, 25(3), 202-232$.

Vázquez, F. S., \& Torres, A. S. (2013). Autism and architecture. Archives of Clinical Psychiatry (São Paulo), 40(2), 85-85.

Verbeek, H., van Rossum, E., Zwakhalen, S. M., Ambergen, T., Kempen, G. I., \& Hamers, J. P.
(2009). The effects of small-scale, homelike facilities for older people with dementia on residents, family caregivers and staff: Design of a longitudinal, quasiexperimental study. BMC Geriatrics, 9(1), 3.

Wagenfeld, A., Roy-Fisher, C., \& Mitchell, C. (2013). Collaborative design: Outdoor environments for veterans with PTSD. Facilities, 31(9/10), 391-406.

Watts, G., Khan, A., \& Pheasant, R. (2016). Influence of soundscape and interior design on anxiety and perceived tranquillity of patients in a healthcare setting. Applied Acoustics, 104, 135-141.

Winz, M. (2018). An atmospheric approach to the citypsychosis nexus. Perspectives for researching embodied urban experiences of people diagnosed with schizophrenia. Ambiances. Environnement sensible, architecture et espace urbain. http://jour nals.openedition.org/ambiances/1163.

Wittchen, H.-U., Jacobi, F., Rehm, J., Gustavsson, A., Svensson, M., Jönsson, B., Olesen, J., Allgulander, C., Alonso, J., Faravelli, C., Fratiglioni, L., Jennum, P., Lieb, R., Maercker, A., van Os, J., Preisig, M., Salvador-Carulla, L., Simon, R., \& Faravelli, C. (2011). The size and burden of mental disorders and other disorders of the brain in Europe 2010. European Neuropsychopharmacology, 21(9), 655-679.

Wu, M. Y., Shen, C.-Y., Wang, E. T., \& Chen, A. L. (2020). A deep architecture for depression detection using posting, behavior, and living environment data. Journal of Intelligent Information Systems, 1-20, 225-244.

Yalçin, M. (2015). "Exploratory" and "Descriptive" aspects of environmental psychology course within the interior design education. Procedia-Social and Behavioral Sciences, 174, 3531-3541.

Zamfir, M.-V., \& Grigorescu, M. Z. (2017). A checklist for assessing dementia-friendly design: Architecture as non-pharmacological mean in assistance of patients with dementia. European Psychiatry, 41, S667. 